The University of Akron

\title{
IdeaExchange@UAkron
}

July 2018

\section{Virtually Sensuous (Geographies): Towards a Strategy for Archiving Multi-user Experiential and Participatory Installations}

Sarah F J Rubidge

University of Chichester, srubidge1@gmail.com

Please take a moment to share how this work helps you through this survey. Your feedback will be important as we plan further development of our repository.

Follow this and additional works at: https://ideaexchange.uakron.edu/docam

\section{Recommended Citation}

Rubidge, Sarah F J (2018) "Virtually Sensuous (Geographies): Towards a Strategy for Archiving Multi-user Experiential and Participatory Installations," Proceedings from the Document Academy: Vol. 5 : Iss. 1 , Article 8. DOI: https://doi.org/10.35492/docam/5/1/8

Available at: https://ideaexchange.uakron.edu/docam/vol5/iss1/8

This Conference Proceeding is brought to you for free and open access by University of Akron Press Managed at IdeaExchange@UAkron, the institutional repository of The University of Akron in Akron, Ohio, USA. It has been accepted for inclusion in Proceedings from the Document Academy by an authorized administrator of

IdeaExchange@UAkron.For more information, please contact mjon@uakron.edu, uapress@uakron.edu. 
This article explores potential strategies for documenting an immersive multi-user digital installation, Sensuous Geographies, using VR technologies. The installation was interactive, fully immersive and participatory, with the general public being the initiators of the details of the installations sonic and visual worlds. It was created in 2003 in collaboration with composer Alistair MacDonald, at a time when the very notion of choreographic digital installations, particularly multi-user interactive installations, was in its infancy.

At the turn of the 21st century, many thought computers and dance strange bedfellows. At that time, the world of the digital was known for its tendency to distance itself from the messy world of sensation. The claim of digital technologists in the 1990s was that in the digital domain one could shake off the physical constraints imposed by the body and gravity (Benedikt, 1992).

Disembodiment and/or dematerialization were considered intrinsic consequences of digital media by virtue of the immateriality of digital information and the assumption that the nature of the user's interaction with media was necessarily estranged from embodiment and corporeality. However, by the 2000s warnings were being sounded by writers such as Richard Coyne, Mark Hanson, Ken Hillis and Hubert Dreyfus that, although on entering cyberspace "we might leave behind our... intuitive, situated... embodied selves, and thereby gain a remarkable new freedom never before available to human beings," we should be aware that "we might, at the same time, necessarily lose some of our crucial capacities" (Dreyfus, 2001, 208). Because dance is an art form that is grounded in the sensation of movement, in the very experience of embodiment, in dancers and choreographers a distrust of digital media and all that it represented was rife.

Nevertheless, in the 1990s a number of choreographers, and their counterparts in theatre, began to explore the potential of a dialogue between the mathematical, scientific and "disembodied" world of digital media and choreographic practice, and to embark on collaborations with programmers and digital artists (Dixon, 2007). Although Merce Cunningham was an early user of digital media in the 1980s, in the 1990s the use of digital media as an integral aspect of choreographic practice emerged in the work of companies such as New York based Troika Ranch, Germany's Palindrome and Australia's Company in Space. Rather than simply integrating a range of digital media into their stage works, their choreographers began to explore the use of interactive media as a means of performers generating the audiovisual environment in which they performed in real-time. This gave dancers the agency they thought they might lose in "digitalized" choreography.

However, from the mid-1990s another strand of digital choreography was making an appearance, with experiments being undertaken by choreographers who were interested in not only working with digital media for the stage, but also in taking their choreographic ideas into the digital domain. A number of 
choreographers became interested in exploring the possibilities of prioritizing the experience of dance and the dancing body as the core of their digitally enhanced work, of developing for visitors' direct experience of the nuanced sense of embodiment and organic sensation possessed by dancers. Working with digital artists, programmers and/or electro-acoustic composers, these choreographers began to create immersive, electronically sensitized installation environments which audiences could inhabit and interact with directly. Amongst them were Gretchen Schiller, Susan Kozel, Ruth Gibson of Igloo $^{1}$ and myself. These choreographic installations ${ }^{2}$ were explicitly participatory, designed for audiences to explore and experience from within, and as such bore more resemblance to digital art installations than to conventional conceptions of choreography.

This move to the experiential was echoed in the theoretical domain, when what became known as Affective, Performative and/or Embodied Turns were making an appearance in the fields of neuroscience, the social sciences, geography, philosophy, psychology, the humanities - and even computer science with the rise of Affective Computing. Thinkers were beginning to pay attention to the contribution embodied knowledge makes to human thought and behavior. For choreographers working with digital media, particularly those working with immersive and interactive installations, the thinking of these scholars both provided unexpected support for, and new insights into their intuitive understandings of the value of embodied knowledge, not only in the generation but also the reception of their artistic work. The work of neuroscientists such as Antonio Damasio, Gerald Edelman and Francisco Varela, geographers such as Nigel Thrift and Derek McCormack, social anthropologists such as Tim Ingold and Edward Casey, and philosophers such as Maurice Merleau Ponty, Gilles Deleuze and Brian Massumi led us to understand more deeply the potentialities of immersive and participatory artworks offered to those who engaged with them. It also indirectly encouraged us to pay more conscious attention to the reciprocal interplay that takes place between the moving body and the environment.

During the first decade of this century, on the few occasions that choreographic installations were mounted in the public domain, the experiential moments they afforded were available only to those who had encountered them physically. The installations ranged from the relatively simple to the highly complex. They included simple one-on-one engagements between installation and participant, installations incorporating complex choreographic systems, and multiscreen, multi-user, interactive/performative environments which were created to

1 Choreographer Ruth Gibson and digital artist Bruno Martelli, now known as Gibson/Martelli. 2 The term choreographic installations is used to emphasize that choreography has two dimensions. The first is the creation of gestural and full-bodied movement for expressive or artistic purposes, and the second is the spatiotemporal organization of movement in general space. Thus an installation can be called choreographic if it addresses either of these features. 
enable visitors to: a) experience both the material and immaterial dimensions of the installations primarily through embodied sensation; b) generate and spatialize the audio/visual environment that they were simultaneously experiencing and responding; and c) engage in both solo and collective interactivity. And in my case, the spatialized audiovisual imagery the installations initiated became an integral part of a digitally-generated but live choreographic event that could be experienced from within, and/or perceived from without.

It quickly became apparent there was a major problem if the aim was to archive the sensory richness of these works. The only visual media that were available to us to record the work audiovisually were video recordings and photographs of the installations in action. Neither these visual traces of the works, nor the written reviews and descriptions of those who had experienced them, or the artists own writings on the works (Kozel, 2008; Rubidge, 2003, 2007; Schiller, 2006) enabled people who had not encountered them to get even a glimpse of the sense of being that engagement the works initiated.

A decade later, I found myself wondering whether it would be possible to recreate the conditions that gave rise to the experience of such works in such a way that the experiential dimensions of the works, which was their raison d'être, could be shared after the fact. The archiving of art and digital media installations has been addressed on some detail in the visual arts (Scholte \& Hoen, 2007; Morcillo et al., 2014), and some solutions found to archiving gallery-based art installations that rely on the visitors' experience of inhabiting the installation. The same cannot be said of the documentation of the choreographic installations made during the early 2000s by virtue of their immersive environments, their interactive engagement, the emphasis on embodied responses and their navigability. The extant audiovisual documentation is more than unsatisfactory. Any video documents that have been made are constrained to the installations events in progress, which can only provide the viewpoint of an observer watching the installation in action. As such they are unable to provide for the viewer even an inkling of the embodied involvement to which the installation gave rise.

\section{Documenting Immersive Installations}

In my work different installations (e.g., Passing Phases in 1994-1999; global drifts in 2006; and Fugitive Moments in 2007) emphasized different issues. Sensuous Geographies was an artistic experiment which addressed all of the above. As such it offers a prime site for research into new modes of the documentation for experiential installations.

Sensuous Geographies was an intricate multi-user interactive installation, in which participants created the multi-layered soundworld to which they were responding. It was fully immersive, with its perceptual interface between the 
audiovisual environment and the visitor dependent not on the visual but on the aural sense. The material installation constituted two physical environments, one "outer," one "inner" (the former embracing the latter). The inner environment, which was surrounded by curved screens, was electronically sensitized to enable it to emit a sonic response to the visitors' behavior as they moved in and through the space. Before entering this area, visitors had to don a colored costume ${ }^{3}$ to become recognizable to the interactive system. From the moment they entered the inner space, they became active participants. The installation used a simple optical motion tracking system ${ }^{4}$ to track the movement of individual participants. Identifying the participants by color recognition enabled the interactive system to locate, identify and track individual participants as they navigated the space. A particular sound strand was "attached" to participants as they entered the inner environment. The texture, intensity and spatial placement of the sound changed in response to the directions and velocity of the participants' movement through the inner environment resulting in multiple sounds being sent simultaneously into the space to create a richly textured sonic choreography.

When Sensuous Geographies was active, attempts were made to document the work. As noted, no media suitable for the documentation of experiential works were available to the artistic community at that time, with the result that the documentation was confined to documents that do not fulfil the requirements of the experiential dimensions of Sensuous Geographies (see Figure 1).
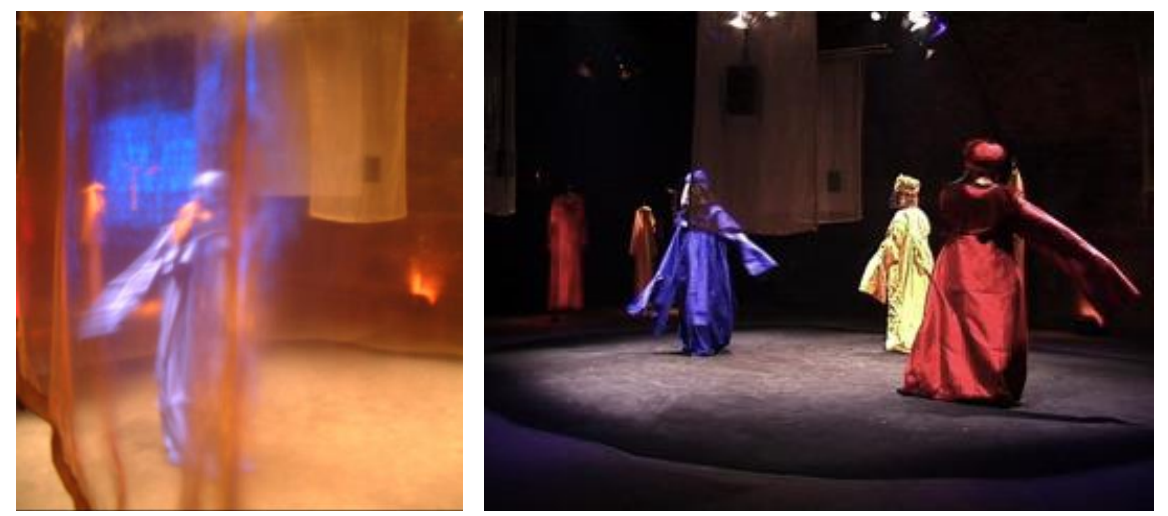

Figure 1. Snapshots of Sensuous Geographies in action (2003)

3 The costumes comprised full length robes of red, blue, green or yellow). Designed by a costume designer, the robes gave the installation a very theatrical ambience.

4 A camera mounted in the ceiling above the electronically sensitized space. 
I was not in a position to address the documentation of digital installations until 2010, when a colleague ${ }^{5}$ and I began to experiment with a simple 3D documentation of two of my installations, global drifts ${ }^{6}$ and Fugitive Moments. ${ }^{7}$ Neither of these installations were digitally immersive, and both were only minimally interactive. Rather they were primarily physical environments into, and onto which choreographed digital imagery was projected, and through which visitors were able to navigate, choosing their own points of view, and determining which imagery to spend time with.

For documentation purposes, because the installations featured multiple screens through which visitors needed to navigate if they were to experience the range of digital imagery embedded in the works, we focused on developing a navigable 3D emulation of the installation environments using a 3D software with simple Games Engine facilities. One of these installations (Fugitive Moments) was displayed in a gallery and comprised two different physical installations which displayed real-time generative digital imagery initiated by a single program on screens in different rooms of an art gallery. The other (global drifts) featured nine screens of various shapes and sizes displaying a range of soft focus digital imagery. These were distributed around the entire precinct of an Australian University. In this work, because more than one screen was visible at any one time to the viewers, the combination of moving imagery on several screens created a rhythmic digital choreography across the site.

Although a step forward in the development of documentation of choreographic installations, our documentation experiment was not entirely successful in significant ways. The 3D Virtual Environments (VEs) we created for both works, using affordable open source software, ${ }^{8}$ were primarily computer generated, navigable visual re-presentations of the installations' material environments and as far as possible re-presentations of their digital imagery. However, the 3D environments and digital imagery lacked the rich texture and affective tone of the visual representations of the screen imagery and the environment in which it was embedded. (Ironically this was present in the more conventional photographic and video documentation.) The 3D versions thus diminished, rather than enhanced, the sense of being physically immersed in the installation environment. As visual textures are a crucial initiator of sensate responses to an environment, a factor of both installations that was integral to

5 Neil Bryant: Media Centre, University of Chichester

6 A collaboration with chorographer Hellen Sky

7 A collaboration with neuroscientist Beau Lotto and programmer Erwin le Martelot 8 Bryant used the Open Source 3D software, Blender for this project. Used most frequently as a Games Engine in the early 2000s, it had the capabilities needed to recreate on screen the navigable environments of these installations. Unfortunately the prototypes we made are no longer accessible, as the programmers upgraded the system in 2011, and in doing so rendered the models we made in the previous system unplayable without recoding the original Blender documents. 
their artistic character was omitted from the documentation. Further, the 3D world was displayed on a 2D screen, from a distance. By virtue of its navigability the documentation was thus only a step up from video documentation. Finally, because the navigation through the environments was achieved through the manual use of a mouse and keyboard, the engagement of the full body that accompanies all activities in a real-world environment was lacking.

As a result, although when engaging with the 3D software viewers could navigate through the installation environment in their own way, they got no embodied sense of the affective tone generated by the installation environment and the audiovisual imagery of the real-world installation. ${ }^{9}$ Nevertheless, the experiments overcame the major difficulty that accompanies the use of video documentation for interactive immersive installation environments in that users had the freedom to choose their own pathway through the installation environments, and thus to some extent direct their own experience.

Consequently, as a means of developing a virtual re-presentation of the visual environment of a navigable immersive installation environment the use of (an affordable) 3D/Games Engine Software alone proved itself to be inadequate on this occasion. It was, however, a valuable ally in the search for a means of documenting one aspect of immersive installations, the physical environment. Thankfully, during the 21st century, the concept of Virtual Environments has been overtaken by Virtual Reality (VR). Hardware and software has changed rapidly, and continues to change and, with it, VR environments. Open Source Games engines are becoming increasingly sophisticated in their rendering abilities and the VR hardware needed to immerse oneself in a computer-generated world is now more affordable, and thus has become more available to artists.

\section{Documenting Sensuous Geographies in VR}

In this article, I forward the suggestion, and rationale, for the documentation of Sensuous Geographies through VR technologies. VR has advanced sufficiently since the piece was made for it to be taken up as a possible means of making available to future audiences and historians an embodied trace of the experience engendered by many immersive choreographic installations works of the 1990s. Through VR visitors of the future would be able to access a moment in choreographic history which has passed into the realms of memory.

However, Sensuous Geographies presents particular problems with regard to creating satisfactory documentation of the installation. I suggest that solving

9 For example, in Fugitive Moments, one of the physical installations was shown in a darkened room with black walls, in global drifts the imagery was only seen at night. These factors have an effect on the physical responses to the installations 
these could serve as a means not only of documenting a single installation, but also of advancing the documentation of immersive installations in general.

Firstly, visitors to the real-world Sensuous Geographies could choose to take two perspectives, that of participant, or that of viewer. As viewers visitors could navigate themselves around the outer environment. In VR models, creating the environment for the "viewers" generates less issues than creating the detail of the sensitized, interactive "inner" space that lies at the heart of the installation. In this space the active participants created an intricate spatial choreography and an everchanging spatialized soundworld as they engaged with the interactive system. As such they created the sonic environment in which they and the visitors in the outer environment were immersed. As the inner environment presents the most pressing issues, and challenges, for documentation purposes it is these that I will focus on in this article.

Because in Sensuous Geographies the multi-layered spatialized sonic environment the participants were responding to was being generated and modulated in real time by their own movement behaviors, visitors and environment were simultaneously acting upon each other in a reciprocal game of action, reaction and interaction. A further complication was embedded in certain conditions imposed on participants in the real-world installation. Their sight was somewhat obscured by a semi-opaque veil that was part of the costume's headdress. ${ }^{10}$ The veil allowed the visitors to see shadows around them as others engaged with the installation from within, and were thus minimally aware of their physical environment, but could not see the space clearly enough to be able to navigate the environment by sight. Instead, hearing became the dominant sense used for navigating the space. The visitors achieved this primarily by "following" the strand of sound they themselves were activating, spatializing and modulating it as they moved around the inner space. Thus, as an ensemble, they created, and choreographed, a layered, spatialized sonic composition. However, as sound has a particularly strong impact on the physiology, not only was the participants' attention to the sonic environment central for choreographic purposes, the installation also drew their attention to the detail of their inner (kinesthetic and proprioceptive) responses as they moved and encouraged them to factor these into their responses to the sonic environment.

Clearly, neither 2D video documentation of participants moving in the installation, nor screen-based navigable 3D emulations of the installation alone, could reflect both the agency the installation afforded the participant with respect to the composition of the sonic environment, and the sensate experience that emerged from it. Therefore, the question I will address here is: how would one

10 The veil was added during the development period to ensure that vision (which is a "distant" sense, in relation to the haptic and aural senses) did not diminish the use of hearing as the primary receptor of the sonic environment. 
simulate the agency afforded participants and at the same time emulate the experiential engagement with the sonic environment when considering a new way of archiving installations such as Sensuous Geographies?

I believe that recent developments in VR technologies can take us some way towards my goal, as VR now has the capacity to achieve for the viewer the physical experience of being fully present in a virtual world through: a) the advent of affordable, sophisticated audiovisual Head Mounted Displays (HMDs); b) advances in audiovisual rendering in, and the interactive capabilities of, Games Engines; c) the increasing attention being paid by VR developers to the interplay between the perceptual senses and the role this plays in our experience of the environment (Ajdler, 2006; Arias et al., 2011; Larsson et al., 2001; Wong et al., 2002).

In order to create a living archive of Sensuous Geographies a satisfactory emulation of the conditions of the installation that gives rise to the sensate experience upon which the operation and reception of the installation depends is required. I suggest that this would be achievable through the capacity of HMDclad "players" to be completely enveloped in the virtual Sensuous Geographies architectural and audiovisual environment. Just as in the real world, in VR there is no "edge of vision" (Brunner, 2012). Even if sight is obscured, simply by moving their heads VR users can not only perceive, but also get a sense of experiencing the 360-degree breadth and depth of the world they are inhabiting, with no break to the "flow" of the illusion of the body being enfolded in the environment.

\section{Perception, the Real World and VR}

It is important at this point to consider how a VR re-presentation of an immersive art installation viewed through an HMD stands in relation to the real-world version. As far back as 1966 psychologist James Gibson noted that in the real world we engage in an intricate interplay between our sensing bodies and the environment (Gibson, 1966, 1986). This interplay affects not only how and where we move, but also the detail of our perceptual responses, and our sense of being. This is echoed in immersive installations, which are designed to enfold the visitor and enhance their attention to nuanced affective features of the world of the work. In order to make this available in VR the aim would be to create the environmental and perceptual conditions that would initiate in the virtual world an analogous experience to that experienced by visitors in the real-world installation.

The importance of the way our perceptual systems operate cannot be overemphasized when developing Virtual Worlds (Regia-Corte et al., 2013). As Gibson posited, the specificity of our perceptual experience is generated by an intricate dynamic network of sensory systems, comprising the visual, the aural, the olfactory, the haptic, the kinesthetic and the proprioceptive. This perceptual 
network is a complex, highly integrated, multi-channel system of perception that absorbs and interprets complex environmental information from all of the senses simultaneously. Consequently, at any moment all of the perceptual channels are simultaneously not only acting upon but also being acted upon by each otherand of equal significance being acted upon by the environment. The shifting orientation and proximity of features of an environment that are generated by our movement within it impact on this perceptual network, enabling us to orient ourselves in an ever-changing, complex, multi-dimensional environment in which not only sight, but also sound and the (proprioceptive) sense of space all contribute to our understanding of where we are and how we feel. We use the same perceptual cues to estimate our position, orientation and affective responses in a virtual world as we do in the real world.

Therefore, all details of an environment, must be considered when building an immersive virtual world. At the simplest of levels, a virtual world with the affective tone that gives us a rich embodied response must feature at least: a) a realistically rendered visual re-presentation of the installation environment, in all its optical subtlety; b) the conditions in which an aural world that takes account of the shifts in sonic texture that occur when different features of an environment are encountered; c) the impact of these and of gravity on the kinesthetic and proprioceptive senses.

With regard to the visual environment, the direction and play of light and changes of intensity of light in an environment modulates its affective tone. In combination with the more material features of an environment VR developers call this the Plenoptic Function (Adelson and Bergen, 1991; Wong et al., 2002). I suggest that this is as true in the experience of a semi-opaque environment as it is of a fully defined world, for these nuanced changes can be sensed without full sight, and therefore equal attention must be paid to them.

Significantly the affective tone and spatial awareness of a VR environment are contingent on information derived from not only visual but also aural channelsto such an extent that a mismatch between the sonic and visual perceptual clues in a virtual world measurably reduce the sense of presence experienced by its visitors (Larsson et al., 2001; Arias et al., 2011; Ajdler et al. 2006). Hence, in VR a rendering is needed of an emergent, spatially distributed multi-layered sonic environment which simulates the spatio-temporal acoustic field that flows from the volume and shaping of the environment. In addition, attention must be paid to the movement of avatars in virtual worlds that give rise to a sonic response which takes account of the location of the avatar in the virtual world in relation to the player. For this simple factor will change the texture of the sound emitted by the avatar for the player. These in combination are known in the VR world as the Plenacoustic function or the environment's acoustic footprint. Thus, the multidimensional and textural dimensions of sound are integral facets of any 
immersive environment and must be given their due in the design of a VR environment. ${ }^{11}$

We also need to give players full control of their movement in the virtual space by providing a navigational interface that allows them to negotiate the space intuitively, and which gives a realistic sense of kinesthetic involvement in the shifts and changes in the VR environment. Highly sophisticated VR representations of museum spaces using Oculus Rift reveal that VR systems, even those developed in 2014, rarely engage this level of kinesthetic involvement. Indeed, VR worlds and representations too often give the viewer a sense of gliding or flying through an environment, unencumbered by gravity. However realistic the visual representation, this diminishes the sense of texture and embodied sense of weight that walking in the real world affords.

In response to navigation systems that did not engage the action of the full body, Norbert Nitzsche and his colleagues addressed the need to develop systems for the intuitive navigation of VR worlds directly (Nitzsche et al., 2004). They argued that, as proprioceptive and kinesthetic senses are an essential element of the spatial perception of an environment, a realistic illusion of walking in a Virtual Environment would require the same estimations of orientation and position as in the real-world. For this reason, the activation of the proprioceptive and kinesthetic systems is a prerequisite of the sensation of navigating in Virtual Worlds. In order to create the conditions that would allow users to use their full gamut of proprioceptive responses in VR, Nitzsche built a real-world user environment for his experiments, complete with motion tracking system (Nitzsche et al., 2004). Users donned an HMD linked to an external computer and navigated the virtual world they were seeing through the HMD by walking as if they were in that world in reality.

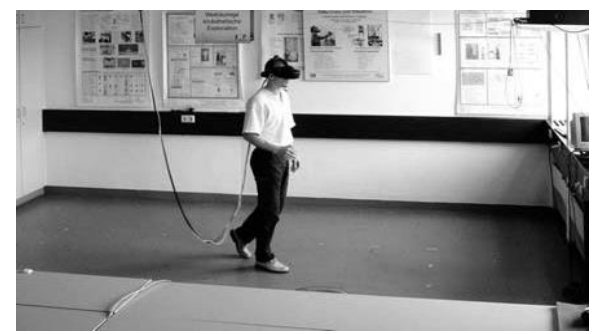

Figure 2. Nitzsche's VR user environment

11 Developments of an audio system for Gaming Worlds that facilitates procedural sound could be of value here (Collins, 2009). 


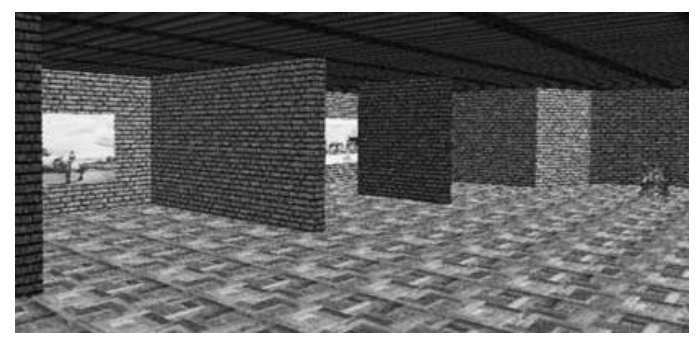

Figure 3. Nitzsche's VR environment navigated by the HMD user

This was made possible by a Motion Compression algorithm, which allows users in a restricted space (Figure 2) to navigate a virtual world (Figure 3) intuitively using not only the visual and auditory systems but also, via the physical act of walking, the proprioceptive and kinesthetic systems. This is integral to what is known as the Plenhaptic function which, as in real-world perception, extends beyond mere touch (as articulated by Gibson, 1966).

Adoption of Motion Compression as a viable interface in VR has given rise to Extended Range Telepresence and is increasingly being incorporated into VR systems (Morcillo et al., 2014; Packi et al., 2010).

Nitzsche's experiments are precursors to the proposed VR renderings of immersive installations such as Sensuous Geographies as they allow the embodied responses which are crucial to a) the activation of the system, and b) the depth of sensory response it initiates. Morcillo and his colleagues have demonstrated the viability of using this in the archiving of media installations and sculptures through their VR re-presentations of media art installations such as Nam June Paik's Versailles Fountain (Morcillo et al., 2014) around which viewers can navigate in a virtual world.

The technology needed for the development of VR re-presentations of three dimensional experiential installations therefore seems to be in place.

\section{Sensuous Geographies and Interactivity in VR}

However, further research, and experimentation with current VR technology, would be needed to create a VR version of Sensuous Geographies that would allow viewers both to engage with the installation as spectators when outside the inner environment, and experience physiologically the emulated audiovisual environment they were creating through their interaction with the virtual world when in the inner space. The installation's bespoke interactive system and sonic samples would need to be ported into a VR program, and potentially modified to enable the VR visitor to Sensuous Geographies to explore what was needed for 
the generation of a) the range of potential modulations of the installation's virtual audio or visual environment, and b) the choreography the sound environment.

Further, the real-world Sensuous Geographies enabled increasingly sophisticated sonic environments and informal group choreographies to be generated as participants became more experienced. Thus, this installation would demand something more than merely emulating the material and sonic environment. The installation enabled participants to approach their interactive engagement with it through increasingly complex dialogues with their fellow participants as they moved through different levels of expertise. The potential for increasingly intricate interactivity was embedded in the detail of the interactive system, as it is in computer games. VR visitors to Sensuous Geographies would therefore, like gamers, need to become familiar with the range of interactive possibilities available to them.

In the real-world installation, when visitors first engaged with the installation as single players the responses of the system were fairly direct, the interactive system responding simply to velocity and/or direction of travel in the space to create a nuanced and mutable sound strand. At this level, participants could also choose individually to choreograph/compose the sonic world spatially by deliberately creating a spatial interplay between their individual sound strands. As participants became more familiar with the environment and the interactive interface they could increase the level of complexity of their engagement with it by opting to engage in two, three- or four-way interactions with others. Here the responses of the interactive system became increasingly complex, as the system introduced in its armory of responsive techniques that of the proximity of one or more other visitors, which operated under particular rule systems which the participants had to discover. And this in itself became increasingly complex, with a number of systems in play that the participants had to discover through experimentation.

Although this aspect of the system was tested out successfully as part of the development of the installation with a group of dancer-choreographers, it was difficult for casual participants to build up sufficient experience as the installation proved to be so popular that access to the sensitized space had to be timelimited. ${ }^{12}$ A VR version would offer the opportunity to test how far the possibilities of becoming increasingly virtuosic in the use of the system out could be taken.

Finally, like gamers, the VR visitors to Sensuous Geographies could be geographically remote, which would require the VR system to accommodate group interactivity under all conditions. As it cannot be guaranteed that several

12 We developed the real-world Sensuous Geographies in collaboration with a consistent group of dancers. Over time they were able to develop a way of working together than gave rise to threeand four-way collective interactivity. 
users would log-in to a virtual Sensuous Geographies at the same time, the multiuser facet of the installation, which enables the real-time composition of a layered and spatially intricate sonic environment, would need to be addressed, perhaps through the introduction into the system of automated avatars which have the ability to respond to other avatars, including those of the live players.

\section{Conclusion}

If one was to approach the archiving of a VR version of Sensuous Geographies with a view to emulating the conditions that gave rise to the embodied experience of the real-world installation, and at the same time facilitate a spectator's viewpoint, the creation of a VR rendering of an installation as complex as Sensuous Geographies would have to have several stages, each addressing different aspects of the real-world installation. These would range from the construction of the virtual installation's "material" environment, through to the importing of the sonic and interactive systems, including systems allowing one, two or three-way interactive behaviors, and finally creating automated avatars should they be needed for VR visitors to engage collectively with the system. Each would present different challenges and need for experimentation.

\section{The Visual Environment}

It would not be difficult to model a navigable VR re-presentation of the material environment of Sensuous Geographies. Plans of the installation environment are available, including clear photographs of the screens that surround the inner environment in full light. Differently colored digital avatars which either represent real players or are automated would need to be written into the system to provide the opportunity for all players to experience multi-user engagement, and thus a semblance of collective interactivity, and those adopting a viewer's perspective to experience a choreosonic event taking place in the inner space.

\section{The Sonic Environment}

Emulating the generation of the sonic world of the inner space, and its impact on the kinesthetic systems, would be more difficult. As sound, even in virtual worlds, has an impact on the physiological systems, the sense of presence engendered by the real-world installation would also need to be there in a virtual Sensuous Geographies. Further, the visitors to the real-world installation had their vision obscured in order to redirect their attention to the soundworld and the responses it initiated in their bodies. However, their vision was not taken away completely, which allowed the full perceptual system to be brought into play. For this reason, 
the nascent visual experience would need to be emulated in the VR environment if the affective tone which gave Sensuous Geographies its power is to be achieved; perhaps by making the representation of avatars and the changing shape of the environment that results from the movement of participants (e.g., proximities of screens and spatial relationships between avatars) look very hazy when users enter the inner environment.

\section{Interactive Behavior}

Emulating the physicality of the interactive behavior needed to activate the environment would be possible using navigational interfaces such as those developed by Nitzsche. As VR has become of interest to more researchers, the Motion Compression algorithm has been adopted and developed for use by VR developers, which would facilitate an embodied sense of a virtual Sensuous Geographies. Although research into full body navigational interfaces suggests that the conditions that gave rise to the experiential sensations could be conserved in a virtual rendering, little research has been undertaken into the effect that subtly changing the audio textures of the environment in response to the behavior of visitors has on the participants.

However, whilst it might not be too much of a problem to re-create Sensuous Geographies in VR if the focus of the interaction was on solo interactivity - that is on the generation and modulation by visitors of a single sound strand or digital image, developing systems for collaborating virtually with other visitors to compose a multi-layered spatialized sonic, or audiovisual world, or developing co-operative interactivity which uses proxemic factors as part of the interactive interface, is less easy to imagine. This would need to be addressed if Sensuous Geographies were to be rendered satisfactorily in VR.

Thus, research into ways of archiving complex experiential installations such as Sensuous Geographies could serve to advance archiving installations in the arts in multiple ways. Its multi-dimensionality and complexity would make it a particularly interesting case for the further development of VR technologies as a means of archiving interactive artworks and exhibitions. As such this installation would be a worthy test of Morcillo's claims that multimodal devices and the adoption of advances in VR technology such as the plenoptic, plenacoustic, and plenhaptic functions, would allow for a more lifelike experience in virtual scenarios (Morcillo et al., 2014). 


\section{References}

Adelson, E. H., \& Bergen, J. R. (1991). The plenoptic function and the elements of early vision. In M. Landy \& J. A. Movshon (eds), Computational models of visual processing (pp. 3-20). Cambridge, MA: The MIT Press.

Ajdler, L., Sbaiz, T., Vetterli, M. (2006). The plenacoustic function and its sampling. IEEE Transactions on Signal Processing, 54(10), 3790-3804.

Arias, A. P., Eberhardt, H. P., Pfaff, F., \& Hanebeck, U. D. (2011). The plenhaptic guidance function for intuitive navigation in extended range telepresence scenarios. IEEE World Haptics Conference, 2011, 475-480. doi: 10.1109/WHC.2011.5945532

Benedikt, M. (1991). Cyberspace: First steps. Cambridge, MA: The MIT Press.

Brunner, C. (2012). Immediation as process and practice of singaletic mattering. Journal of Aesthetics and Culture, 4(1), article 18154. doi: 10.3402/jac.v4i0.18154

Collins, K. (2009). An introduction to procedural music in video games. Contemporary Music Review, 28(1), 5-15.

Coyne, R. (1999). TechnoRomanticism: digital narrative, holism and the romance of the real. Cambridge, MA: Leonardo.

Dixon, S. (2007). Digital performance: A history of new media in theater, dance, performance art, and installation. Cambridge, MA: The MIT Press.

Dreyfus, H. (2001). On the internet. London and New York: Routledge

Fazenda, B. (2011). Recreating the sound of Stonehenge. Paper presented at The Acoustics of Ancient Theatres Conference, Paris, France.

Gibson, J. J. (1966). The senses considered as perceptual systems. Boston, MA: Houghton Mifflin.

Gibson, J. J. (1986). The ecological approach to visual perception. Hillsdale, NJ: Laurence Erlbaum Associates.

Grau, O. (2003). The database of virtual art: For an expanded concept of documentation. Paper presented at International Cultural Heritage Informatics Meeting, Paris, France. Retrieved from www.archimuse.com/publishing/ichim03/016C.pdf

Hanson, M. (2000). Embodying technesis: Technology beyond writing. Ann Arbor: University of Michigan Press.

Hillis K. (1999). Digital sensations. Minneapolis: University of Minnesota Press

Kozel, S. (2008). Closer: Performance technologies, phenomenology. Cambridge, MA: The MIT Press.

Larsson, P., Västfjäll, D., Kleiner, M. (2001). Ecological acoustics and the multimodal perception of rooms: real and unreal experiences of auditory-visual virtual environments. In Proceedings of the 2001 International Conference on Auditory Display, Espoo, Finland, July 29-August 1, 2001 
(pp. 245-249). Available at https://smartech.gatech.edu/handle/1853/50203

Morcillo, J. M., Faion, F., Zea, A., Hanebeck, U. D., Robertson-von Trotha, C. Y. (2016). E-installation: Synesthetic documentation of media art via telepresence technologies. In M. Boştenaru Dan \& C. Crăciun (Eds.), Space and time visualisation (pp. 173-191). Cham, Switzerland: Springer.

Nitzsche, N., Hanebeck, U. D., \& Schmidt, G. (2004). Motion compression for telepresent walking in large-scale remote environments. Presence, 13(1), 44-60.

Packi, F., Pérez Arias, A., Beutler, F., \& Hanebeck, U. D. (2010). A wearable system for the wireless experience of extended range telepresence. In R.

C. Luo (Ed.), Proceedings of the 2010 IEEE/RSJ International Conference on Intelligent Robots and Systems (IROS 2010), Taipei, Taiwan (pp. 5226-5231). Piscataway, NJ: Institute of Electrical and Electronics Engineers.

Regia-Corte, T., \& Marchal, M., Cirio, F., \& Lécuyer, A. (2013). Perceiving affordances in virtual reality: Influence of person and environmental properties in perception of standing on virtual grounds. Virtual Reality, $17(1), 17-28$.

Rubidge, S. (2003). Sensuous geographies: a multi-user interactive/responsive installation 2001-2003 research report. Available at http://www.sensedigital.co.uk/writing/SGResRep.pdf

Rubidge, S. (2003). Spaces of sensation: The immersive installation and corporal literacy. Paper presented at International AILA Conference on Literacy, Ghent University, Belgium.

Rubidge S. and A Macdonald. (2004). Sensuous geographies: A multi-user interactive/responsive installation. Digital Creativity, 15(4), 245-252.

Rubidge, S. (2007). Sensuous geographies and other installations: Interfacing the body and technology. In S. Broadhurst (Ed.), Performance and technology, practices of virtual embodiment and interactivity (pp. 112126). London, UK: Palgrave Macmillan.

Rubidge, S. (2009). The technological poetics of global drifts. In D. Tercio (Ed.), Perspectivas sobre dança em expansão tecnológica [Perspectives on technologically expanded dance] (pp. 119-137). Lisbon, Portugal: Faculdade da Motoricite Humana.

Rubidge, S. (2009). Performing installations: towards an understanding of choreography and performativity in interactive installations. In J. Butterworth \& L. Wildschut (Eds.), Contemporary choreography: A critical reader (pp. 362-378). London, UK: Routledge.

Schiller, G. (2006). Kinaesthetic traces across material forms: Stretching the screen's stage. In S. Broadhurst \& J. Machon (Eds.), Performance and 
technology: Practices of virtual embodiment and technology (pp. 100111). Basingstoke, UK: Palgrave MacMillan.

Scholte, T. \& Hoen, P. (Eds.). (2007). Inside installations, preservation and presentation of installation art. Amsterdam, Netherlands: Instituut Collectie Nederland.

Wong, T.-T., Fu, C.-W., Heng, P.-A., \& Leun, C. S. (2002). The plenoptic illumination function. IEEE Transactions on Multimedia, 4(3), 361-371. 